\title{
¿Es el pensamiento transhumanista una amenaza a la dignidad humana?
}

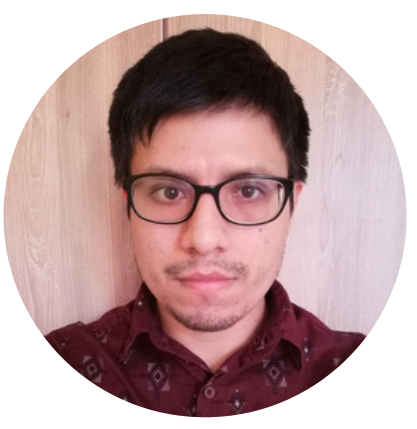

\section{JULIO SILVA CÉSPEDES iD https://orcid.org/0000-0002-0931-7528}

Estudiante de Filosofía en la Universidad Nacional Mayor de San Marcos. Miembro del instituto de extrapolítica y transhumanismo (IET) y del grupo de investigación Sentido y Referencia (UNMSM). Principales áreas de investigación: historia de la filosofía, filosofía de la mente, lógica y ética. Ha expuesto sus trabajos en eventos como el XVII Congreso Nacional de Filosofía (2019), el Primer Simposio Internacional de Lógica (2019) y el VIII Coloquio de Filosofía Latinoamericana (2020).

\section{julio.silva9@unmsm.edu.pe $\triangleright$ Filosofarte}

Resumen. Este ensayo examina críticamente la tesis - defendida por filósofos bioconservadores - que sostiene que el pensamiento transhumanista constituye una amenaza a la dignidad humana. A partir de esta consideración, defenderemos las siguientes tesis: primero, el pensamiento transhumanista nos conduce a replantear la noción de dignidad humana para hacerla más amplia y ofrecer, en su lugar, la noción de dignidad de los seres sintientes; segundo, la principal preocupación no es si llegasen a existir tales seres (los transhumanos), sino si es que tales seres serán lo suficientemente moralespara lidiar con grandes poderes tecnológicos.

Palabras clave: bioconservador, igualdad humana, dignidad humana, especismo, transhumanismo

\section{Introducción}

Durante las últimas décadas, el debate sobre el uso de las tecnologías del mejoramiento humano ha aumentado en el campo de la ética aplicada. En el año 2009, los filósofos Nick Bostrom y Julian Savulescu (2009) publicaron una recopilación de ensayos que daban cuenta del debate hasta ese entonces. En esa recopilación se puede apreciar no solo las implicancias prácticas del uso de las tecnologías del mejoramiento humano, sino también las implicancias filosóficas, pues, por ejemplo, el uso de este tipo de tecnologías incita a reflexiones en torno a la naturaleza humana, la identidad personal, el bienestar, el estatus moral, etc. Pues bien, uno de los principales debates gira en torno a la noción de dignidad humana. Algunos bioconservadores califican al pensamiento transhumanista como una amenaza a la dignidad humana $y$, en consecuencia, se oponen categóricamente al uso de las tecnologías del mejoramiento humano.

En este ensayo, se examinarán los argumentos ofrecidos por algunos bioconservadores para, posteriormente, defender la siguiente tesis: el uso de las tecnologías del mejoramiento humano nos obliga a repensar la noción de dignidad humana, pues esta noción es especista; además, la inserción de este tipo de tecnologías nos debe conducir a una ampliación de nuestra esfera de consideración moral y ofrecer, en lugar de la noción especista, la noción de dignidad de los seres sintientes.

\section{¿Qué es el transhumanismo?}

El transhumanismo es un modo de pensar acerca del futuro. Se basa en la idea de que la actual naturaleza humana no representa el fin último de nuestro desarrollo. Formalmente, podemos definirlo como:

"El movimiento cultural e intelectual que afirma la posibilidad y la deseabilidad de mejorar fundamentalmente la condición humana a través de la razón aplicada, especialmente desarrollando y elaborando tecnologías ampliamente disponibles para eliminar el envejecimiento y mejorar en gran medida las capacidades humanas físicas, intelectuales y psicológicas" (Bostrom, 2003, pág. 4).

Si en el futuro se lograran desarrollar tecnologías tales como la nanotecnología molecular, la superinteligencia, el mind uploading (la transferencia de la mente a una computadora) o alguna otra igualmente revolucionaria, la condición 
humana cambiaría de manera radical. Sin embargo, el transhumanismo no depende necesariamente de la realización de tales tecnologías. La realidad virtual, el diagnóstico de preimplantación genética, la ingeniería genética, los productos farmacéuticos que potencian la actividad mental, las drogas que mejoran la ejecución de ciertas actividades, la medicina antienvejecimiento, el interfaz humanocomputadora; todas estas tecnologías ya están aquí o pueden ser esperadas dentro de un par de décadas. La combinación de estas capacidades tecnológicas podría transformar profundamente la naturaleza humana (Bostrom, 2005, pág. 12).

Una de las preocupaciones principales - hacer que tales tecnologías estén disponibles para todas las personas de manera segura - cada vez se volverá más relevante en los próximos años.

\section{La posición bioconservadora}

En oposición a la visión transhumanista, se erige la posición bioconservadora que arguye contra el uso de la tecnología para modificar la naturaleza humana. Prominentes defensores del campo bioconservador incluyen a Leon Kass, Francis Fukuyama, George Annas, entre otros.

Una de las preocupaciones centrales de los bioconservadores es que el uso de las tecnologías del mejoramiento humano es deshumanizador $y$, en ese sentido, socavan algo que es profundamente valioso en el ser humano, a saber, su dignidad humana. Así, Francis Fukuyama (2002) ha identificado al transhumanismo como la idea más peligrosa del mundo y ha manifestado su preocupación:

"La negación del concepto de dignidad humana esto es, de la idea de que hay algo único en la raza humana que concede a cada miembro de la especie humana un mayor estatus moral que el resto del mundo natural - nos llevaría por un camino muy peligroso" (pág. 160).

La principal y legítima preocupación de otro bioconservador, George Annas, es el prospecto de la violencia y de la opresión:

"Los mejorados posthumanos inevitablemente llegarían a ver a los "naturales" como inferiores, como una subespecie de humanos adecuados para la explotación, la esclavitud o incluso la exterminación. Finalmente, es este prospecto de 10 que podría denominarse "genocidio genético" lo que hace de la clonación, junto con la ingeniería genética, un potencial arma de destrucción masiva, y un potencial bioterrorista al biólogo que 10 intentase" (citado en Savulescu 2009)
Así, el problema que surge es el siguiente: si llegasen a existir seres que logren tener mejoradas sus capacidades físicas e intelectuales mediante el uso de las tecnologías del mejoramiento humano, ¿nuestro estatus moral sería degradado? ¿Es el pensamiento transhumanista una amenaza a la dignidad humana?

Ahora bien, para poder responder a esta pregunta, es importante primero aclarar lo que se entiende por igualdad humana, pues se suele argumentar que la igualdad se basa en la dignidad humana.

\section{¿lgualdad humana?}

Cuando alguien afirma que todos los seres humanos, independientemente de su raza, credo o sexo, son iguales, ¿qué es lo que realmente está afirmando? El problema es que no es cierto que, literalmente, todos los seres humanos sean iguales. Es innegable que los humanos, considerados individualmente, tienen diferentes cualidades: algunos son más altos que otros, algunos tienen mayor fuerza física que otros, algunos tienen mejores habilidades mentales que otros, etc. Entonces, la idea de igualdad humana no es una afirmación literal sobre cómo son los seres humanos.

Ahora bien, poniendo de ejemplo el caso de la esclavitud, se podría defender la idea de la igualdad humana señalando lo siguiente:

"No hay diferencias biológicas conocidas entre los esclavos y las personas libres. Las leyes humanas habían convertido a algunas personas en esclavos y a otras, en amos. Entre blancos y negros existen algunas diferencias biológicas objetivas, tales como el color de piel y el tipo de cabello. Pero no hay evidencia de que esas diferencias se extiendan a la inteligencia o la moralidad" (Harari, 2014, pág. 120).

En ese sentido, se podría defender la idea de que todos los seres humanos tienen igual capacidad intelectual y facultad moral, y que las diferencias que vemos en la realidad se deben, en última instancia, a factores meramente sociales y no biológicos. Todo aquel que se oponga al racismo, sexismo, o cualquier otra forma de discriminación arbitraria desearía que las cosas fueran de ese modo, es decir, desearía que las diferencias entre los individuos se deban a factores puramente sociales - esto significaría que con cambios sociales adecuados se eliminarían las diferencias entre las capacidades físicas e intelectuales de los individuos. Sin embargo, esta argumentación presenta dificultades.

El problema con este tipo de argumento es que 
no podemos tener una garantía absoluta de que estas capacidades y facultades se distribuyan por igual entre los seres humanos, sin tener en cuenta la etnia ni el sexo (Singer, 2018, pág. 20). En consecuencia, no podemos tener una garantía absoluta de que en un futuro no se llegue a descubrir que la diferencia entre esas capacidades y facultades no se deben solo a factores sociales. ¿Qué sucedería si se llegase a descubrir que algunas diferencias importantes se deben a factores biológicos? La respuesta es que, en ese caso hipotético, quienes se oponían a la discriminación mediante ese tipo de razonamiento tendrían que acabar admitiendo que, en cierta medida, la discriminación podría ser defendible.

Por lo tanto, la idea de igualdad humana no debe fundarse en la presuposición de que, en principio, todos los seres humanos tienen las mismas capacidades físicas y facultades mentales, independientemente de factores biológicos. Entonces, ¿qué es la igualdad humana?

"La igualdad es una idea moral, no la afirmación de un hecho. (...) El principio de la igualdad de los seres humanos no es una descripción de una supuesta igualdad real entre ellos: es una norma relativa a cómo deberíamos tratar a los seres humanos" (Singer, 2018, pág. 21).

\section{Dignidad humana y especismo}

Ahora bien, una vez aclarada la idea de igualdad humana, la pregunta que surge es la siguiente: ¿en qué se basa? La respuesta que suele ofrecerse es que se basa en la dignidad humana. La noción de dignidad humana confiere un estatus moral a los seres humanos, especialmente el derecho inalienable a ser tratados con un nivel básico de respeto. Sin embargo, esta respuesta es problemática.

Cualquier defensa satisfactoria de la afirmación de que los seres humanos, y solo ellos, tienen dignidad intrínseca tendría que apelar a características relevantes que solo los seres humanos posean. Sin embargo, la única cualidad que poseen de manera absoluta todos los seres humanos es que pertenecen a la especie Homo sapiens. No hay otra cualidad absolutamente compartida por todos los seres humanos y que los diferencie completamente de los demás animales. No todos son racionales (los humanos con muerte cerebral no son seres racionales, por ejemplo). No todos son altruistas o compasivos. Los seres humanos no son los únicos animales sociales o políticos. Pero, cacaso la mera pertenencia a una especie es un criterio moralmente relevante para conferir derechos a dicha especie y no a otras? Por supuesto que no. Se puede comparar esta justificación con otros tipos de discriminación arbitraria. Por ejemplo, el enunciado "la razón por la cual solo los blancos poseen ciertos derechos es que son blancos" tiene la misma estructura que el enunciado "los seres humanos poseen ciertos derechos simplemente porque son humanos".

Por tanto, al ser comparable el especismo con el racismo, se puede apreciar que se necesita una fundamentación más apropiada para la noción de dignidad humana. Se necesita un criterio moral relevante, y la mera pertenencia a una especie no es un criterio moral relevante. ¿Qué ofrecer en su lugar?

\section{Repensar la dignidad humana: la dignidad de los seres sintientes}

Hay objetos en el mundo que no tienen intereses porque no pueden sufrir, y cualquier cosa que hagamos no afectaría su bienestar. Una piedra, por ejemplo, no sufriría si la pateamos. Pero, hay también en el mundo seres que sí tienen intereses. Un ratón, por ejemplo, tiene un interés en no sufrir, y al patearlo afectaríamos su bienestar. En consecuencia, la capacidad de sufrir es una condición necesaria para que podamos afirmar que un ser tiene interés en no sufrir.

A partir de lo anterior, podemos considerar la siguiente reflexión ética:

"Cuando un ser sufre, no puede haber justificación moral para no tomar en consideración ese sufrimiento. Con independencia de cuál sea la naturaleza de ese ser, el principio de igualdad exige que el sufrimiento sea tenido en cuenta con el mismo derecho - en la medida en que tal comparación pueda hacerse - que el de cualquier otro ser. Si un ser es incapaz de sufrir, o de experimentar alegría o felicidad, no hay nada en él que tenga que ser tomado en cuenta. Esta es la razón de que el límite de sensitividad sea la única frontera defendible de nuestro interés por los intereses de los otros. Marcar esa frontera por alguna otra característica como la inteligencia o la racionalidad sería elegida de un modo arbitrario ¿Por qué no elegir entonces alguna otra característica, como el color de la piel, por ejemplo?" (Singer, 2003, pág. 114).

Es decir, el criterio moralmente relevante para fundamentar la dignidad humana debe ser la sensitividad (capacidad de sentir dolor o placer). En un sentido estricto, ya no se consideraría dignidad 
humana, sino más bien dignidad de los seres sintientes. En consecuencia, lo que debemos hacer es expandir nuestra esfera de consideración moral hasta incluir a todos los seres que tengan sensitividad. Esta tesis cada vez es más aceptada en los ámbitos académicos y sociales (la defensa de los derechos de los animales no humanos es un claro ejemplo).

Antes de terminar este punto es importante señalar que hay otros factores que hacen que la vida de un ser sea más valiosa que la vida de otros como, por ej., la austoconsciencia, la racionalidad, la capacidad de planear el futuro, tener relaciones interpersonales, etc. Es por esta razón que la vida de muchos humanos es más valiosa que la de algunos otros seres: tenemos otras cualidades moralmente relevantes que otros seres no poseen, aparte de la sensitividad. Sin embargo, compartimos con muchos otros seres el criterio moral básico de sensitividad, y esta es una condición necesaria para otorgar a un ser el derecho a la igualdad, esto es, igual consideración del interés básico que es no sufrir.

\section{Conclusiones}

Finalmente, podemos considerar que el transhumanismo constituye una amenaza a la digni- dignidad humana - este concepto considerado como especista - , pero no a la dignidad de los seres sintientes. Por tanto, dadas las razones ofrecidas, lo moralmente apropiado es repensar la dignidad humana y optar por la defensa de la dignidad de los seres sintientes.

Este tipo de defensa está acorde con el artículo número siete de la Declaración Transhumanista: "7.Nosotros abogamos por el bienestar de todo ser sintiente, incluyendo humanos, animales no-humanos, cualquier futura inteligencia artificial, formas de vida modificadas, $u$ otras inteligencias que se podrían originar con el avance científico y tecnológico." (Bostrom et al, 2009)

Entonces, la preocupación principal no debe ser la posible existencia de seres humanos mejorados física e intelectualmente, sino el asegurar que "el mundo posthumano sea lo suficientemente moral. Nosotros debemos temer mucho de los posthumanos inmorales. Pero entonces de nuevo, hoy tenemos mucho que temer de los humanos inmorales con grandes poderes tecnológicos." (Savulescu, 2009, pág. 239)

\section{Referencias}

Bostrom, N. (2003). World Transhumanist Association. The Transhumanist FAQ: A General Introduction: //nickbostrom.com/views/transhumanist.pdf

Bostrom, N. (2005). A history of transhuanist thought. Journal of Evolution and Technology(14). www.nickbostrom.com/papers/history.pdf

Bostrom, N., et al. (2009). Transhumanist Declaration. Humanity+: https://humanityplus.org/philosophy/transhumanist-declaration/

Bostrom, N., \& Savulescu, J. (2009). Human Enhancement. Oxford University Press.

Fukuyama, F. (2002). Our Posthuman Future: consequences of the Biotechnology Revolution. Farrar, Strauss and Giroux. Harari, Y. (2014). Sapiens: a brief history of humankind.Signal.

Savulescu, J. (2009). The Human Prejudice and The Moral Status of Enhanced Beings: What Do We Owe the Gods? En N. Bostrom, \& J. Savulescu (Edits.), Human Enhancement (pp. 211-247). Oxford University Press.

Singer, P. (2003). Desacralizar la vida humana: ensayos sobre ética. Cátedra.

Singer, P. (2018). Liberación animal. Taurus.

\section{Cómo citar este artículo:}

Silva, J. (2021). ¿Es el pensamiento transhumanista una amenaza a la dignidad humana? Futuro Hoy, 2(2), 2528.https://doi.org/10.52749/fh.v2i2.4

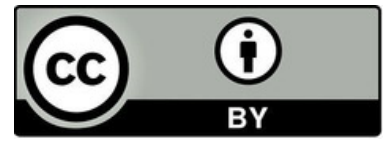

Esta obra está bajo licencia internacional Creative Commons 4.0 Reconocimiento 4.0. 